\title{
O ENSINO DA FILOSOFIA SEGUNDO HEGEL: CONTRIBUIÇÕES PARA A ATUALIDADE ${ }^{1}$
}

\author{
Pedro Geraldo Aparecido Novelli ${ }^{2}$
}

- RESUMO: É possível ensinar filosofia? O filósofo alemão G. W. F. Hegel (17701831) não somente responde afirmativamente à questão posta, como também indica o que deve ser ensinado e como em filosofia. A resposta hegeliana tem como fonte sua atividade como diretor do ginásio de Nürnberg, onde ele procura estabelecer diretrizes e procedimentos para que a filosofia seja ensinada aos jovens. Segundo Hegel, a filosofia sempre é pertinente na medida em que se manifesta sobre o que é fundamental para o homem, isto é, sobre sua vida com as questões que lhe dizem respeito. Para tanto, a filosofia deve assumir o homem como seu objeto de consideração. Isto deve resultar na apreciação da realidade humana para que a partir dela sejam levados e elevados à sua maior e melhor compreensão pela reflexão e pela especulação. Tais habilidades não são adquiridas senão pelo contato direto com a filosofia em sua especificidade na sua produção histórica, ou seja, nos textos. Conhecer a história da filosofia já é aprender filosofia, mas tal aprendizagem necessita da mediação do professor. A mediação se faz necessária, pois a aprendizagem não é natural e, portanto, não se dá espontaneamente. Aprender é sempre aprender com alguém.

- PALAVRAS-CHAVE: abstração, dialética, especulação.

\section{Introdução}

A educação tem merecido ao longo dos tempos atenção especial de muitas áreas do conhecimento. O interesse da filosofia pela educação re-

1 Artigo recebido em 05/2005; aprovado para publicação em 07/2005.

2 Departamento de Educação, Instituto de Biociências, Universidade Estadual Paulista Júlio de Mesquita Filho, Unesp, 18610.000, SP, Brasil; pnovelli@ibb.unesp.br 
monta aos gregos antigo,s como evidenciam a "República" de Platão, a "Ética à Nicômaco" de Aristóteles, dentre outras. Na modernidade autores como Rousseau, Kant, etc. confirmam a preocupação com a educação. Percorre entre os pensadores de ontem e de hoje a tese da educação como o momento privilegiado da formação do homem, pois se trata de uma possibilidade formal e intencional de realização e promoção das sociedades humanas. A própria filosofia pode ser tomada como um momento da educação com aspectos e características específicos. O pensador alemão G.W.F. Hegel (1770-1831) deteve-se particularmente sobre a filosofia e sua relação com a educação por ocasião de sua função de diretor de ginásio em Nürnberg entre os anos de 1806 e 1816. Nesse período Hegel estava intensamente envolvido com a organização do ensino da filosofia para os jovens, e são também desse período os seus principais escritos sobre o ensino da filosofia. Aqui são tomados três textos nos quais Hegel trata do ensino em geral e da filosofia.

O primeiro texto é um parecer elaborado para o real conselheiro superior da Baviera, Immanuel Niethammer, no qual Hegel se manifesta sobre o significado da filosofia para os jovens do ginásio. Num país assolado pelas repercussões dos fatos ocorridos na vizinha França, Hegel se pergunta sobre as motivações e as razões para a insistência no ensino da filosofia. Como pode ainda a filosofia contribuir para que um país se constitua como tal? A resposta hegeliana se traduz na consideração da metodologia que se mostrava, nessa época, fortemente direcionada pela perspectiva pragmática. A metodologia não é, segundo Hegel, somente a determinação do como fazer, mas também do porquê e do que fazer.

O segundo texto é uma breve carta também dirigida ao conselheiro Niethammer. Em poucas linhas, mas em tom bastante marcante, Hegel se posiciona com respeito ao conflito entre forma e conteúdo. Contra a tendência que os contrapõe também através da disputa sobre o que é atual e ultrapassado, Hegel busca a superação da exclusão para insistir na completude entre os opostos.

Finalmente, o terceiro texto é uma carta dirigida ao real conselheiro do governo prussiano e professor Friedrich v. Raumer, na qual Hegel explora o ensino da filosofia nas universidades. A universidade é tida, por Hegel, como o local mais adequado para o ensino da filosofia porque aí se pode esperar e exigir dos alunos determinadas posturas que somente a maturidade proporciona. Tal maturidade deve permitir o exercício da paciência e da demora sobre o conceito para que o todo seja alcançado e o real, por sua vez, verdadeiramente compreendido.

A questão do ensino da filosofia em Hegel não somente revela suas idéias sobre o processo pelo qual uma dada área do conhecimento deve ser transmitida, mas também sua concepção sobre a educação na qual a figura 
do professor ocupa a posição central. Para Hegel, o aprendizado é sempre uma atividade mediada, pois não se dá de forma natural ou espontânea. A mediação realiza-se no embate entre o que predomina e insiste em permanecer como está e o que daí brota, ou melhor, como sua negação sob o aspecto de superação, como um vir-a-ser. Com isto evidencia-se que a tarefa do professor não se caracteriza pela calmaria da adequação, mas sim pela agitação do que desestabiliza para se estabelecer.

\section{A educação em Hegel}

Hegel atribui grande importância à educação muito embora não tenha escrito nenhum tratado sobre tal tema. Sua época foi marcada por intensos debates sobre a educação, principalmente no que diz respeito à sua popularização. Esta foi uma das conseqüências da Revolução Francesa, que também empreendeu esforços de maior inclusão do povo na vida do Estado. O movimento iluminista foi outro elemento que contribuiu para fomentar o debate em torno da educação. Em seu tempo, Hegel também vive de perto a tendência à literatura educativa. Suas leituras de juventude incluem o "Emílio" de Rousseau, que lhe causou profunda impressão.

"Seu herói era Rousseau, de quem ele freqüentemente leu 'O Emílio', 'Do Contrato Social' e 'Confissões'” (Rosenkranz, 1844, p. 430).

As atividades profissionais desempenhadas por Hegel ao longo de sua vida atestam seu envolvimento com a educação. Hegel foi preceptor privado, professor e diretor de ginásio, conselheiro escolar da cidade de Nürnberg, tornando-se responsável por toda a atividade docente da cidade, professor e reitor universitário e consultor do governo para as questões educacionais. Deve-se mencionar ainda que a maior parte da docência hegeliana se passou durante a reforma educacional na Alemanha, liderada por Niethammer. A universidade de Berlim, onde Hegel atuou como professor e posteriormente como reitor, assumiria as mudanças orientadas por Humboldt.

Portanto, Hegel não se encontrava afastado da problemática que envolvia a educação, e se em sua obra filosófica não se apresenta uma consideração explícita e determinante sobre a mesma, não se pode tranqüilamente concluir que não há aí uma visão pedagógica. De fato, não há proposta pedagógica que não contemple uma compreensão de homem e da relação deste com o mundo. A preocupação com a educação de alguém traz, inserida em seu bojo: por que isto é necessário, como é possível fazê-lo e para quê. Certamente pode-se dizer que isso nem sempre é reconhecido, mas evidencia-se pela direção escolhida e pelas opções feitas como o ser humano é compreendido e, conseqüentemente, como deve ser tratado. De igual 
modo pode-se dizer que todo sistema filosófico também contém uma proposta pedagógica, pois se trata de elucidar o homem a respeito de si mesmo e de seu mundo.

No caso de Hegel é necessário mencionar que sua associação às tendências pedagógicas de sua época não era harmoniosa. Segundo Hegel, a pedagogia estaria excessivamente preocupada com situações periféricas em relação à educação que se traduziam na concentração sobre os métodos e as técnicas:

(...) el clamor de la pedagogía moderna, que toma en cuenta sólo las exigencias de nuestra época y las necesidades inmediatas, afirmando que, tal como para el conocimiento lo primordial es la experiencia, así para la idoneidad en la vida publica y privada las especulaciones teóricas son más bien perjudiciales; y que lo único que se requiere es la ejercitación y la educación prácticas, que son lo substancial. (Hegel, 1968, p.27)

A crítica de Hegel à influência do momento tem como fundamento uma compreensão de homem que não se deixa determinar unicamente pelo aqui e agora, mas que procura manter em foco a totalidade do que ocorre, isto é, as relações entre o que aí já está e o que começa a ganhar corpo. Hegel comunga com as diversas tendências pedagógicas o fato de que todas afirmam o homem, mas ele se dissocia daquelas que situam o homem demasiadamente no âmbito da natureza:

O homem aparece depois da criação da natureza e constitui o oposto ao mundo natural. É o ser que se eleva ao segundo mundo. Temos em nossa consciência universal dois reinos: o da natureza e o do espírito. O reino do espírito é o criado pelo homem. Podemos forjar-nos todo tipo de representação sobre o que será o reino de Deus, mas ele sempre há de ser um reino do espírito que deve ser realizado no homem e estabelecido na existência. (Hegel, 1989 a, p.59)

O homem se caracteriza por se construir e ao fazê-lo ele acaba por construir seu próprio tempo, seu próprio mundo. Suas construções são a construção de sua liberdade que somente é sabida e reconhecida na medida em que se efetiva, ou seja, se realiza. O que o homem é aparece no que resulta de seu agir enquanto desejado e quisto. Dessa forma o homem extrapola o limite do natural no qual ele se depara com o que ele não quis e ainda não se reconhece. Ao romper as determinações do natural o homem também reconhece esse natural, e agindo sobre ele o homem se abre para além de si mesmo. Aqui reside a abertura para a educação.

Ao se abrir para a exterioridade o homem se abre para uma outra realidade que não ele mesmo. O ser do homem se revela no ser de um outro que, como ele, se revela pela relação que pode ser entendida como auto-revela- 
ção. A relação ocorre primordialmente como história, ou seja, no que é pensado, feito e desejado, em suma,no que é realizado. A história é o espaço por excelência das relações travadas pelo homem principalmente porque se trata aí de saber que se faz e o que se faz. O pensado, o feito e o desejado são a confirmação da atividade humana, que quanto mais se reconhece nisso tudo tanto mais se apropria do próprio ser. Na história o homem deve ser o que pode ser. É um dever ser porque lhe é pedido que se adapte ao momento e suas circunstâncias e que as assuma como sendo de sua autoria. De forma imediata, o homem é tão-somente a possibilidade de ser, de ser livre e racional. Contrariamente ao animal, o homem não se educa pelo seu simples robustecimento, mas pela necessidade de ser que ele obtém pela superação do natural. No âmbito do natural o homem recebe sua determinação de fora, e a superação de tal estágio se traduz pela autodeterminação do homem. Isto também significa a transformação do natural segundo os interesses humanos. A aquisição e o desenvolvimento da disciplina já denota um avanço em relação ao natural, pois se trata de um regramento que é escolhido, aceito e cultivado. Com tal procedimento o homem afirma que nem tudo pode ser feito ou feito a qualquer momento, nem em qualquer lugar. A determinação do comportamento como o que se quer e reconhecimento de si no que se quer é a caracterização da liberdade conforme Hegel a compreende: "(...) se a vontade é verdadeira e absolutamente livre, o que ela quer ou o seu conteúdo nada mais pode ser do que ela própria. Só pode querer em si mesma e ter-se a si mesma como objecto" (Hegel. 1989 b, p. 262).

A aceitação do regramento é o entendimento da liberdade como uma realidade que somente é possível com o outro e pelo outro. É pelo outro que o eu se promove e pode ser mais o que é. Também pode ser menos. O que é certo em Hegel é que sem o outro o eu não subsiste. Desta forma o eu não se preserva sem a concomitante preservação do outro. Por isso, com o outro nem tudo é permitido ou aconselhável. Então, se a história é o resultado das relações entre os homens, afirmá-la é a conseqüente afirmação da pertença a um povo, isto é, da participação numa relação maior. Nesse sentido, para Hegel, ninguém se educa sozinho, e somente estando inserido em seu povo é que ele pode com êxito se educar. Tal inserção implica conhecer o que seu povo tem feito. Faz-se necessário o acesso à tradição de seu povo, e daí poder participar dos conhecimentos até então desenvolvidos e elaborados, apreendê-los e sabê-los, torna-se seu direito e tarefa. O objetivo não é a redução do indivíduo ao dado histórico, mas o reconhecimento deste para aí se reconhecer, pois cada um fará sua leitura do que já é partilhado por todos. "É unicamente na vida de um povo que a intuição intelectual se torna ao mesmo tempo uma intuição real, ao passo que os olhos do espírito e os olhos do corpo coincidem" (Hegel, 2002, p.53). 
A educação proporciona o segundo nascimento do indivíduo, elevando-o do estágio natural ao social, tornando-o autônomo ou senhor de si no convívio de seu povo. A autonomia é uma conquista do indivíduo porque este precisa aderir à proposta de seu povo, isto é, ao que significa conviver num determinado contexto, e renunciar suas particularidades e exclusivismos. Não se trata de abrir mão de interesses individuais, mas sim individualistas, que pretendem a imposição do particular ao universal inclusive com o sacrifício deste. A autonomia não se dá no âmbito da natureza reduzida ao em si de si mesmo, ou seja, enclausurada numa existência determinada. A educação diz respeito à existência de indivíduos e de como estes vêm a ser individualidade coletivizada e coletividade individualizada, a saber, como os indivíduos se reconhecem em seu povo e como seu povo os reconhece.

Para Hegel, aprender é aprender com alguém, por intermédio de alguém, isto é, por um processo necessariamente mediado. Sem intervenção não se pode esperar que a educação se realize. A consciência em Hegel não é um ensimesmamento nem uma auto-suficiência. Assim, a pedagogia hegeliana remete muito mais a uma antropologia, ou seja, à compreensão do que é e como o homem vem a ser. O homem, segundo Hegel, é uma contínua passagem, um contínuo vir a ser; sempre como filho de seu tempo, do que o precedeu e do que está por vir como resultado de sua própria atividade.

O homem não somente está na base de toda educação, mas é a própria base da educação. Por isto, de certo modo, nenhuma educação poderia deixar de ser uma educação humanista mesmo quando seu conteúdo se refere ao natural ou ao exato.

Esta é a perspectiva que Hegel vê no mundo grego, que se identifica com a realização do homem. Portanto, o estudo da cultura grega expresso no interesse pela língua e filosofia é um procedimento natural. O homem derivado do mundo grego é aquele que se direciona pela eticidade, pela razão e pelo espírito despojado de suas contingências. Saber e conhecer o que os gregos sabiam e conheciam significa garantir a formação de homens guiados pela razão e pelo espírito.

Contudo, isso não implica um retorno ao passado ou na busca de um paraíso perdido. Isso, aliás, seria impossível, no entender de Hegel. A implicação é o benefício da saída de si e da posição na qual o sujeito se encontra para se deparar com as riquezas do espírito humano advindas de outras culturas e histórias, e saber-se membro de uma comunidade que extrapola os limites do localizado no aqui e agora. É assim também que a universalidade é alcançada e o indivíduo se eleva de sua particularidade. Além disso, a leitura dos gregos antigos permite ao indivíduo do presente confrontar o próprio tempo com questões que talvez tenham sua pertinência estendida para além de sua origem. "Da mesma maneira que Anteo renovava suas forças através do contato com a terra materna, assim também todo novo impulso 
e consolidação da ciência e da cultura avançaram mediante retorno à Antigüidade" (Hegel, 1970, p.314).

\section{Hegel e o ensino de filosofia}

O período vivido por Hegel também demonstra a resistência à filosofia pela tendência pragmática que entendia a teoria como algo danoso.

La doctrina exotérica de la filosofía kantiana - es decir, que el intelecto no debe ir más allá de la experiencia, porque desde otra manera la capacidad de conocer se convierte en razón, teorética que por sí misma sólo crea telarañas cerebrales - justificó, desde el punto de vista científico, la renuncia al pensamento especulativo. (Hegel, 1968, p.27)

O lugar que cabe à filosofia, segundo Hegel, é o do olhar da totalidade que se interessa pela floresta e não somente pela árvore. Não se deve identificar, em Hegel, a atenção dedicada à totalidade como um olhar generalista que não se especifica ou não se determina. Como o próprio Hegel escreve em seus "Princípios da Filosofia do Direito"

Uma vontade que jamais se decide sobre coisa alguma não é uma vontade efetiva, real; de igual modo o homem sem caráter nunca chega a decisão alguma. A razão da indecisão pode residir no fato de que a escolha significa uma limitação, um envolvimento com o finito que nega o infinito. Muito embora tal disposição sejqa bela, ela é, contudo, morta. (Hegel, 2000, p. 64)

A filosofia sempre corre riscos se ela se compromete com o seu tempo. Este comprometimento não desconsidera as questões particulares ou localizadas, mas não reduz sua análise ao dado imediato. Daí, as várias relações precisam ser tratadas para que a fragmentação do real seja superada. Hegel sabe que o homem vive no imediato, mas não pode fazê-lo sem mediação sob o risco de se tornar presa do momento que sempre se põe como exclusivo. É interessante mencionar sobre este aspecto a sugestão de Hegel de que o ensino de filosofia para os ginasianos, de acordo com sua experiência em Nürnberg, considere inicialmente as questões mais imediatas ou próximas do cotidiano, por terem sua existência confirmada e estabelecida na vida diária. Somente então se deve partir para "elevar a consciência para o mais alto, para o pensamento" (Hegel, 1989 b, p.367). Contudo, Hegel aponta que o ensino de filosofia não se deve render ao interesse único pelo imediato, pois mesmo este já está envolto por questões que exigem um certo distanciamento para serem respondidas. Por isso, a filosofia, para Hegel, ganha voz e vez quando se trata de reunir o que se separou. Hegel ilustra 
muito bem em sua "Fenomenologia do Espírito", que apesar de o sensível ser o ponto de partida, ele não é adequadamente compreendido em si mesmo. É no momento seguinte, no caso o momento da percepção, que o sensível se revela inclusive para si mesmo, e pode então ser mais e melhor compreendido.

A filosofia lida com as sombras criadas pela atividade humana tanto em seu cotidiano quanto nas ciências. Tais sombras se traduzem nas imprecisões ou indeterminações que acabam por reger a existência humana precisamente por serem desconhecidas. Todas as ciências e o agir humano possuem um arcabouço teórico mais ou menos consciente, que serve de sustentação e de justificativa para que se faça ciência e se viva no dia-a-dia exatamente como tem sido até então praticado. Essas posturas filosóficas devem ser identificadas e assim é possível visualizar a compreensão de realidade e agir sobre elas:

O bem conhecido em geral, justamente por ser bem-conhecido, não é reconhecido. É o modo mais habitual de enganar-se e de enganar os outros: pressupor no conhecimento algo como já conhecido e deixá-lo tal como está. Um saber desses com todo o vaivém de palavras, não sai do lugar - sem saber como isso lhe sucede. (Hegel, 1992, p. 37)

Além disso, comumente se compreende a filosofia como algo que está ao acesso de todas as pessoas indiscriminadamente, o que, por conseguinte, não exigiria grandes esforços para conhecê-la, pois bastaria fazer uso da razão para emitir um juízo caracterizado pela atividade filosófica. "Só para filosofar é que não se exigem nem o estudo, nem a aprendizagem nem o esforço" (Hegel, 1988, p.73).

Ao contrário, para Hegel, a filosofia exige empenho reflexivo e analítico, o que não se obtém preso à avalanche dos interesses materiais. Desta forma, a filosofia não deve sofrer uma popularização, mas o povo deveria ser elevado ao nível da filosofia. Hegel não é favorável às concessões e facilitações, mas ao mesmo tempo não desconhece o contexto dentro do qual a filosofia é praticada. Nem todos têm os requisitos necessários para o exercício filosófico, porém é possível tê-los na medida em que se submeterem à empreitada que se deve assumir para adquirir o exigido. A filosofia, como tal, possui um conteúdo específico na medida em que se interessa por certos temas e de um modo todo particular, do qual o indivíduo, interessado no exercício do filosofar, deve se apropriar. A apropriação do conteúdo da filosofia implica a concomitante e necessária apropriação da também perspectiva filosófica. Hegel insiste nesse aspecto ao sustentar a primazia do conteúdo em relação àquele que o apreende.

Da mesma forma que as plantas não somente exercitam suas forças reprodutivas através do contato com a luz e com o ar, mas que também nesse processo absor- 
vem seu alimento, de igual modo a matéria pela qual se desenvolve e se exercita o entendimento e a atividade anímica em geral, devem se constituir em alimento. (Hegel, 1970, p. 319)

Filosofar é apropriar-se de um conteúdo que é acessível pelo desenvolvimento de atitudes condizentes com o almejado. Contrariamente a Kant, segundo o qual não se aprende filosofia, mas tão somente a filosofar, Hegel sustenta não haver diferença entre aprender filosofia e aprender a filosofar, pois somente é possível aprender a filosofar aprendendo filosofia. A apreensão da história da filosofia exige o exercício do filosofar visto que o que constitui o objeto desse exercício é o pensar ordenado e claramente, o buscar construir o conhecimento, o valorizar condutas, o normatizar politicamente tais condutas, ou seja, eleger o bem, o justo e o belo.

Dessa forma, para Hegel, não se aprende filosofia como se aprende uma outra ciência. A filosofia demanda a radicalidade, o rigor e a totalidade. As ciências naturais e empíricas repousam sobre o dado imediato e, por isso, perdem o alcance da totalidade, posto que vislumbram o consenso baseado na evidência. O consenso é exatamente, desde a perspectiva filosófica, a assunção de algo que se determina e que tem pretensão de totalidade. A posição determinada, delimitada é precisamente a condição para a própria superação e afirmação de sua insuficiência. É próprio da filosofia o perguntar, o indagar, a partir daquilo que é dado, pois este é entendido como algo passível de novas e diferentes análises. Especialmente em Hegel a filosofia é entendida como uma atenta observação do que assume forma na história. É a partir de sua inserção na história que a filosofia se manifesta e se sustenta. A própria reação ao que se estabelece, isto é, o reconhecimento e a crítica ao real, já indicam que, para Hegel, não se trata de se render ao que predomina como o definitivo e o único possível:

Pensar é o ir-para-dentro-de-si do espírito e, assim, transformar em objecto o que ele é enquanto intui; é o recolher-se em si e, deste modo, separar-se de si. (...). Eis o que constitui o trabalho infinito do espírito: retirar-se da sua existência imediata, da vida natural feliz, para a noite e a solidão da autoconsciência e, a partir da sua força e poder, reconstruir pensando a realidade efetiva e a intuição dele separadas. A partir da natureza da coisa, esclarece-se que justamente a vida natural imediata constitui o contrário do que seria a filosofia, um reino da inteligência, uma transparência da natureza para o pensamento. Semelhante discernimento não se constitui assim tão facilmente para o espírito. A filosofia não é um sonambulismo, é antes a consciência mais desperta, e o seu despertar sucessivo é justamente a elevação de si mesmo para lá dos estados da unidade imediata com a natureza - uma elevação e um trabalho que, enquanto diferença incessante de si em relação a si, para suscitar de novo a unidade mediante a actividade do pensamento, incidem no decurso de uma época e, claro está, de um longo tempo. (Hegel, 1991, p.52-3) 


\section{O ensino da filosofia nos ginásios}

Hegel já havia desenvolvido e até publicado parte de suas idéias filosóficas durante sua atividade docente na universidade, iniciada em Jena; mas em Nürnberg, ao assumir a direção do ginásio local, ele empreende um esforço significativo de traduzir a filosofia, assim como suas idéias, para os jovens.

Hegel reconhece as especificidades do ginasiano e, por isto, tem por objetivo preparar os indivíduos para a recepção de certos conteúdos e também para o interesse pelos mesmos: "(...) é mais fácil fazer-se incompreensível de uma forma sublime que ser compreensível de uma forma coerente, e que, a instrução da juventude e a preparação da matéria para ela constitui a última pedra de toque da claridade" (Hegel, 1978 p.176).

O objetivo do ensino da filosofia aos jovens seria despertar neles o pensamento especulativo que gradualmente conduziria ao estudo sistemático da filosofia. O sentido comum atribuído à especulação considera esta como um caminhar a esmo, sem direção e sem jamais atingir uma positividade. Em Hegel, a especulação é compreendida como a síntese das determinações da reflexão e da intuição intelectual. O que Hegel pretende é a superação da dicotomia teoria-prática, análise e empiria, e isto é o que opera a especulação que reconhece tanto uma quanto a outra, e que ainda indica uma relação absoluta entre ambas. A separação entre razão e sentidos, sujeito e objeto é fictícia e pretenciosa porque afirma o caráter absoluto de um e de outro. Isto é, para Hegel, uma inverdade, pois não há sujeito sem objeto, ou seja, a diferença é identificadora pela aproximação e pela unidade e não pela separação. Nesse sentido, a característica principal da Spekulation em Hegel é a da união de pensamentos e coisas, opostos e entendidos como distintos. Tal união é levada por Hegel às últimas conseqüências Isto significa que o que pode ser conhecido é conhecido diretamente e não por imagens. Portanto, Hegel não assume o termo Spekulation como espelho, pois ele não aceita a idéia de que algo não possa ser acessível por meio da cognição direta. Em suma, a Spekulation em Hegel é a afirmação do sujeito com o objeto, no objeto e pelo objeto. Não se trata somente de que o sujeito reconheça o objeto, mas que se reconheça nele, sendo desta forma um com o objeto.

Movido pela consciência da totalidade, Hegel vislumbra a necessidade de uma formação geral do jovem, para que este possa perceber as relações de complementaridade entre as diversas áreas do conhecimento. Se a filosofia é a percepção do todo, então é necessário estabelecer condições para que esse todo seja percebido. Assim, o processo de formação deve contemplar tal aspecto. Não é sem motivo que Hegel procura adequar o conteúdo aos seus jovens alunos, inclusive com a diminuição do número de aulas 
destinadas ao ensino da filosofia. No entanto, na medida em que as aulas são realizadas, Hegel julga necessário ser metódico para que o aluno receba criticamente o conteúdo que já está na posse do professor. Fica saliente aqui que Hegel atribui a centralidade do processo educacional e, em particular, do ensino de filosofia ao professor que deve assumir tal posição como responsável imediato.

A centralidade do professor se expressa e se confirma na determinação do conteúdo a ser trabalhado, mas isto não significa que o professor não deva ser sensível à realidade do aluno. Tal realidade é a mesma com a qual ele se depara no dia-a-dia e que, para ele, tem profunda pertinência, muito embora não seja sempre reconhecida: "Pela minha parte nada mais sei do que começar pelo Direito, a mais simples e mais abstrata conseqüência da liberdade, passar em seguida à Moral e desta avançar para a Religião como o grau mais alto" (Hegel, 1970, p.404).

Hegel parece ter como pano de fundo para o ensino da filosofia o mesmo processo de manifestação do espírito que, por sua vez, vai do mais sensível ao mais inteligível. Apesar da necessidade de se começar pelo sensível, Hegel faz notar que não se trata de um momento desprovido de pensamento. O mais imediato ou o próprio existente já é pensamento, o que significa que a introdução à filosofia não é mera preparação para o pensar, mas já é o pensar.

Contudo, não se pode perder de vista o fato de que o sensível é um momento que deverá ser ultrapassado até o que Hegel considera ser "o grau mais alto" para o discente, que é o "espiritual teorético, o lógico, o metafísico e o psicológico". Hegel compara a lógica e a psicologia, dizendo que a primeira é mais fácil por se tratar de abstrações mais simples, enquanto a psicologia já faz uso do concreto, isto é, o espírito que envolve a complexidade de sua determinação e compreensão. Mesmo assim a psicologia pode ser facilitada quando se concentra sobre sua abordagem empírica. A psicologia, como Hegel a entende, passa pela consideração de temas como a consciência, a autoconsciência e a razão, graus do sentimento, intuição, representação, imaginação, etc. A metafísica, segundo Hegel, é contemplada pela lógica, pois Kant já havia demonstrado que "o metafísico é uma consideração do entendimento e da razão" (Hegel, 1970, p. 406). Obviamente Hegel considera a lógica kantiana insuficiente e se propõe com a sua lógica objetiva a dar à ciência a dimensão que lhe convém. Entretanto, Hegel insiste na necessidade de se conhecer a fundo o pensamento kantiano para que somente então se possa empreender a avaliação de sua "insuficiência ou rudeza", como ele mesmo afirma.

Nesse sentido entende Hegel que além da lógica e da filosofia do espírito é necessário que os alunos possam conhecer a filosofia da natureza. Segundo Hegel, o jovem de seu tempo não possui o interesse desejável pela 
natureza por se prender a uma postura de "um passatempo teorético" em relação à mesma.

A estética é outra área que Hegel considera ter sido pouco ou quase nada explorada com os alunos do ginásio. Aliás, ele entende que este espaço é o mais propício para o ensino da estética, visto que os alunos poderiam se beneficiar de informações e conhecimentos sobre a arte no geral e ainda ter acesso a determinados expoentes dessa área. Hegel parece estar particularmente mais interessado nas tendências desenvolvidas ao longo dos tempos do que nas orientações de um fazer determinado da arte e para a arte:

Mas seria muitíssimo útil, se os ginasianos, além de um maior conceito de métrica, recebessem também conceitos mais determinados acerca da natureza da epopéia, da tragédia, da comédia e coisas semelhantes, A Estética poderia, por um lado, proporcionar as novas e melhores vistas da essência e do fim da arte mas, por outro, não deveria permanecer um simples palavrório acerca da arte; poderia empenhar-se nos gêneros particulares da poesia e nos peculiares modos poéticos antigos e modernos, introduzir no trato característico com os melhores poetas das diferentes nações e épocas e apoiar com exemplos esse trato. Seria esse curso tanto mais rico quanto mais agradável; conteria apenas conhecimentos que, para os ginasianos, são altamente convenientes (...). (Hegel, 1970, p.409)

Com respeito à metodologia a ser adotada, Hegel critica a distinção comum em seu tempo entre o sistema filosófico e o próprio filosofar, atribuindo tal postura à influência da pedagogia moderna que relegava o conteúdo a segundo plano. Nas palavras de Hegel, isso seria equivalente ao “(...) viajar e viajar sempre, sem chegar a conhecer as cidades, os rios, os países, os homens, etc." (Hegel, 1970, p.410).

Na concepção de Hegel, aprender a aprender ocorre quando se aprende algo, e no aprendizado de algo já está necessariamente contido o aprender. Por isso, não basta a perspectiva formal que cria capacidades e predispõe para o exercício intelectual. Faz-se necessário o conteúdo que deve ser apreendido e, que, por sua sistematicidade, exige a assunção de uma tal postura de aprendizagem que não pode ser nem fortuita nem descontraída. A fixação na formalidade somente inviabiliza a apreensão do conhecer como deve ser, isto é, na sua totalidade. A dificuldade não é característica da filosofia, mas de toda forma de conhecimento que se proponha a ultrapassar a exposição fragmentária e assistemática.

A filosofia se aprende, nas palavras de Hegel, como qualquer outra ciência, ou melhor, o indivíduo deve ser submetido ao conteúdo específico da filosofia, e a partir daí, formular e executar sua compreensão, pois não há preparação prévia para o pensar que não seja a efetivação do próprio pensar. Quem aprende um determinado conteúdo deve necessariamente fazê- 
lo por si só. Não há outro caminho possível, pois se trata da afirmação do próprio sujeito que aprende:

Por muito que o estudo filosófico seja em si e para si um fazer por si mesmo, é igualmente uma aprendizagem - a aprendizagem de uma ciência já existente, formada. Esta é um patrimônio de conteúdo adquirido, formado, elaborado; este bem hereditário deve ser adquirido pelo indivíduo, isto é, ser aprendido. (Hegel, 1970, p. 412)

O conhecimento filosófico está inicialmente na posse do professor, e posteriormente, através dele, é apropriado pelo aluno. Este somente aprende a pensar se tiver sobre o que pensar. Neste sentido professor e aluno não estão no mesmo nível, porquanto o professor já teve acesso a conhecimentos que lhe permitem considerar a realidade muito mais amplamente do que o aluno. No caso da filosofia, não se trata de qualquer forma de conhecimento e, por isto, não é aprendido de qualquer modo. Cada ciência tem suas exigências e a filosofia demanda de seu aprendiz disciplina, concentração e insistência. A disciplina para o estudo regrado e sistemático, a concentração para a atenção acurada à 'fala' do outro, especialmente quando escrevem e a insistência para perseverar na tarefa de compreender o outro e poder manifestar-se sobre ele. Uma vez que o aluno esteja na posse das idéias filosóficas, então ele tem condições para superar "a peculiaridade natural do pensar, isto é, a contingência, o arbítrio e a particularidade da opinião". (Hegel, 1970, p.412)

Hegel entende que o conteúdo filosófico tem três formas bem distintas: abstrata, dialética e especulativa. A forma abstrata é a mera apreensão do pensar como atividade intelectual. A forma dialética exemplifica a contestação das determinações estabelecidas pela abstração, e a forma especulativa é a superação das fragmentações operadas tanto pela abstração quanto pela dialética. Para os ginasianos, o adequado é a aquisição da perspectiva da abstração que abandona momentaneamente o apoio dos sentidos a fim de concentrar-se sobre o indivíduo em sua interioridade. Se o abstrato é o momento inicial, a questão que se põe é como desenvolvê-lo. Hegel reconhece dois caminhos possíveis: o primeiro é ir do sensível ao abstrato, e o outro é partir do próprio abstrato. Quanto ao primeiro caminho, Hegel aponta dois problemas. Em primeiro lugar o caminho que conduz ao abstrato através do sensível pode ser o caminho mais natural, mas precisamente por isto não é o mais científico, pois o que se espera alcançar não é dado pela coisa mesma, mas pensado anteriormente a ela. Em segundo lugar, o caminho pelo sensível não é o mais fácil porque se caracteriza pela apresentação fragmentária e desconexa de cada elemento sensível. Contudo, não basta o abstrato por si só, ou seja, que não se determine por um conteúdo. A abstração pressupõe um dado conteúdo que somente é possível na medida em 
que se operou a elaboração de uma determinação, isto é, do pensar sobre e para o mundo:

Se apenas se adere à forma abstrata do conteúdo filosófico, tem-se uma (chamada) filosofia intelectualista e, enquanto no ginásio se tem a ver com a Introdução e a Matéria, aquele conteúdo inteligível, aquela massa sistemática de conteúdos, é imediatamente o filosófico enquanto matéria, e é introdução, porque a matéria é em geral o primeiro para um pensar efetivo. (Hegel, 1970, p.414)

O dialético é o segundo grau da forma e é, de acordo com a apreciação hegeliana, mais difícil e talvez também menos interessante para o aluno. Difícil porque se trata de se deparar com as posições que avaliam as determinações postas pelo abstrato. O momento dialético é o da contestação do antecedente através de novas determinações que ganham visibilidade muito mais pelo embate que promovem do que por si mesmas. Por isso, o momento dialético também pode ser visto como pouco interessante, pois não se trata de "concreção" e nem de "realização". Hegel sugere que nesse momento as antinomias kantianas tenham seu espaço, apesar de afirmar que as mesmas não passam de "antíteses mal contorcidas" que ele entende ter, "com mérito", elucidado em sua Lógica! O que Hegel critica aqui em Kant é que não se evidencia nas antinomias que um novo conceito brote de um já existente, o que confirma e atesta em Kant uma compreensão estática da realidade que não consegue contemplá-la de forma adequada e verdadeira.

O terceiro momento é o do especulativo, pelo qual os opostos são compreendidos em relação uns com os outros ou, em outras palavras, como um. Trata-se no especulativo o que Hegel denomina "a unidade dos opostos" e o que é "genuinamente filosófico". Hegel ainda enfatiza esse momento definindo-o como a verdade, e cabe lembrar aqui que tal definição reporta ao texto da "Fenomenologia do Espírito", no qual o todo é a verdade! O especulativo é apresentado como o momento mais difícil em relação aos anteriores, certamente por exigir a perspectiva do todo e a adoção da compreensão dinâmica desse mesmo todo.

O especulativo manifesta-se em duas formas, sendo uma próxima à representação e a outra caracterizada pelo conceito. A forma da representação ou da imaginação traduz uma realidade conceitual através das formas, manifestações e expressões que ela possa assumir. No entanto, essa etapa não contempla a totalidade, pois não trata da realidade em si por entendêla inacessível, permanecendo numa compreensão fragmentada da mesma. Essa é a idêntica caracterização que Hegel atribui a Kant, que não consegue aplicar mais do que uma qualificação contrastante ao objeto. O mundo, por exemplo, ou é finito ou infinito, mas não pode ser finito e infinito ao mesmo tempo. Segundo Hegel, Kant padece da dificuldade de ir além do 
imediatamente presente, e conseqüentemente tem grandes dificuldades de tornar objetivo o que é subjetivo. É próprio da representação trazer a uma forma dada, ou ao presente, o que tem existência em si, mas o re-presentar não se funda na identificação com a coisa ou o objeto. O esforço de Hegel é o de proporcionar aos seus ginasianos a perspectiva de que a totalidade da realidade ou a realidade mesma é completamente acessível ao homem. Porém,, este homem somente chega à totalidade do real se assume o caráter dialético desta, que não se resume somente aos seus momentos de afirmação. Este estágio é atingido através da fase conceitual da especulação que une os opostos,superando a postura que os dissocia ou que elimina um para afirmar o outro. "O concebido, e isto significa o especulativo que promana da dialética, é unicamente o filosófico na forma do conceito" (Hegel. 1970, p.415).

O conceito é apreendido e aprendido pelos alunos com muita dificuldade, reconhece Hegel, e somente com muita dedicação e paciência se pode pretender que ele seja entendido pelos jovens. Aliás, diz Hegel, se os alunos aprenderem não é possível certificar-se totalmente de que eles apreenderam adequadamente devido à dificuldade dessa forma. Não se pensa abstratamente senão através de abstrações que, por sua vez, se constituem na preparação para o pensar especulativo. Mas o ensino ginasial é propedêutico ou introdutório, e neste sentido trata-se do local ideal para que tais predisposições sejam estimuladas, ensinadas e desenvolvidas nos jovens. Para Hegel não há melhor meio para a aquisição da especulação do que um conteúdo que a contemple, e tal conteúdo é encontrado na filosofia. Isto indica que a aprendizagem da filosofia passa necessariamente pelo contato com os textos filosóficos. Desta forma Hegel justifica o conhecimento da filosofia antiga que, mesmo devido à sua distância no tempo em relação ao presente, merece atenção e consideração. Não se conhece tão bem a filosofia antiga quando se tem acesso e contato com sua expressão nos textos escritos. Ao responder sobre a pertinência da filosofia antiga para os jovens, Hegel enfatiza que se trata do reconhecimento da própria história humana que se apóia no presente no que a precede. A eloqüência verbal procurada em sua época não pode garantir a necessária formação de um povo, pois o que importa é o que permite que a fala seja consistente e necessária.

\section{O ensino da filosofia nas universidades}

Em carta ao real conselheiro do governo prussiano e professor Friedrich Raumer, Hegel manifesta-se particularmente sobre o ensino da filosofia nas universidades que ele, aliás, considerava o local ideal para o tratamento adequado da mesma. Segundo Hegel, a filosofia deve partilhar com as de- 
mais ciências o fato de ser clara, profunda e minuciosa, mas como sofreu as mesmas adequações das outras ciências também herdou a dificuldade do estabelecimento de procedimentos científicos: "Vemos por um lado, cientificidade e ciências sem interesse, por outro, interesse sem cientificidade" (Hegel, 1970, p.419).

Em 1816 já se percebe na Alemanha a preocupação com uma reforma significativa em seu sistema de ensino universitário, e Hegel vê com suspeitas as possibilidades que se vislumbram porque muitas disciplinas "antigas" (Lógica, Psicologia Empírica, Direito Natural, etc.) estavam perdendo seu significado, sendo mantidas apenas pela sua forma sem se atentar devidamente para o conteúdo específico de cada uma delas. Hegel atribui tal estado à tendência facilitadora do ensino de sua época, que acabava por fazer concessões em termos de conteúdo e exigências aos alunos. Isto se traduzia na concentração sobre o que era considerado necessário, e este era compreendido como a apresentação do que pudesse ser o mais sintético possível, evitando-se assim a concepção compendiosa das ciências e da filosofia, tida como supérflua e até contrária e inferior à idéia. A pressa, como critério para intensificar o conhecimento, já se manifestava nos tempos de Hegel que era contraposta pela postura crítica e cética, mas que, apesar da atitude questionadora em relação ao apressamento no ensino, não avançava no estabelecimento de um estudo adequado da ciência, pois permanecia na negação de um conhecimento rápido sem chegar a instituir ou apontar uma outra possibilidade.

A criação de fórmulas que possam sintetizar conhecimentos filosóficos pode ser atraente no início, mas revela logo em seguida suas limitações porque o todo não pode ser tratado sem que suas partes sejam também pensadas.

Mas as conseqüências derivadas (...) penúria de conhecimentos, ignorância tanto dos conceitos filosóficos como também das ciências especiais, encontram nas experiências do Estado e ainda na precedente formação científica uma oposição demasiado séria e uma repulsa prática, para que aquela obscuridade não caísse no descrédito. Assim como a íntima necessidade da filosofia implica que ela seja elaborada cientificamente e nas suas partes, assim me parece também ser este o ponto de vista adequado à época (...). (Hegel, 1970, p.421)

Se se trata de elaborar uma nova proposta de filosofia, então esta não deve se resumir às ciências antigas, mas, por outro lado, não se pode ignorar o que essas mesmas ciências acumularam e desenvolveram ao longo dos ıpos. O que é novo sempre força seu caminho, e sua recepção não é uma acolhida tranqüila, mas precisa enfrentar a reação do que existe e já possui aceitação. Uma nova filosofia ou um pensar livre não deve ser entendido como uma filosofia ou um pensar absolutamente espontâneos, ou seja, que 
retiram suas motivações de si mesmos, mas que num primeiro momento aprenderam e apreenderam o que os precede para, somente então, empreenderem uma expressão que lhes seja específica. O que é específico somente se põe se reconhece o que se distingue dele, vale dizer, as demais especificidades. Por isso, entende Hegel que o método mais adequado para o ensino da filosofia, assim como de outras ciências, na universidade deve obrigatoriamente pensar os "pormenores".

O que a filosofia considera tem implicações sobre "como", ou o modo que ela deve considerar. A filosofia somente pode ser bem ensinada se ela se determina, e ao se determinar ela se torna evidente, comunicável. A filosofia, em Hegel, não se basta a si mesma, mas tem sua sustentação no ser para. Ela está no mundo e é do mundo que retira sua matéria de reflexão. Deste modo, a filosofia é um bem comum.ou deve se tornar um bem comum, mas para tanto deve ser comunicável. Engana-se, afirma Hegel, que tornar a filosofia comunicável signifique apoiar-se na filologia que, entretanto, se empregada, deve se constituir em meio para a comunicação da filosofia e não em seu fim. Tornar a filosofia comunicável significa apreender o que tem sido feito pelos homens o que aparece expresso nas ciências positivas. Estas unem em si o espiritual e o natural. Estes aspectos são sempre o trabalho da filosofia e, portanto, conhecer as ciências empíricas só pode resultar numa concepção mais profunda da própria filosofia. Se a filosofia promove a predisposição para as outras ciências, então estas são de certo modo filosóficas. Portanto, nada mais desejável que a filosofia mantenha estreita relação com as ciências sem abandonar sua especificidade:

Como ciência propedêutica, a filosofia deve sobretudo proporcionar a educação formal e o exercício do pensar; só conseguirá tal mediante o total afastamento do fantástico, por meio da determinidade dos conceitos e de um procedimento conseqüente e metódico; deve poder conservar esse exercício numa elevada medida como a matemática, porque, como esta, não tem um conteúdo sensível. (Hegel, 1970, p.424)

Finalmente, pergunta Hegel, qual seria o objetivo de se ensinar filosofia aos jovens? Seria a edificação deles? Não, responde Hegel. A filosofia deve se ater a justificar o que possui valor perante o conhecimento de tal maneira que o preserve de deturpações e desvios sempre amparada no pensamento. Embora a filosofia possa investigar o bem, isto não a torna boa, assim como não a torna bela tratar do belo, etc. Não é função imediata nem primeira da filosofia dizer às pessoas o que elas devem fazer, mas sim mostrar o que as pessoas têm feito. Tal demonstração já apresenta algumas indicações sobre o fazer e seus objetivos, mas não como uma postura de adiantamento em relação à história ou ao que acontece. A manifestação da filosofia é posterior ao acontecido. A lógica, a filosofia da natureza e a filosofia do espírito 
são as ciências da filosofia que os alunos precisam aprender para compreender adequadamente o real ou as questões que, de fato, são de interesse dos homens. As ciências da filosofia são a consideração do que vai do abstrato ao concreto de modo que o universal seja plenamente alcançado. Alcançar o universal é a tarefa do sujeito que precisa reconhecer-se em tudo de forma que nada escape à sua ação, sem a qual não se pode falar em existência efetiva. Hegel não somente põe o sujeito no lugar que lhe é de direito, como Kant já havia feito, isto é, o centro, mas também permite que ele supere sua centralidade em sua unidade com o mundo. Daí, aprender filosofia não é tão somente aprender a estar no mundo, mas principalmente aprender a ser o mundo no mundo.

\section{Conclusão}

A atividade filosófica de Hegel é marcada pelo intenso e constante envolvimento com o ensino da filosofia. Praticamente toda a sua vida acadêmica sempre esteve ligada ao ensino. De certa forma pode-se dizer que Hegel atualiza ou realiza sua filosofia através do ensino. No esforço para ser compreendido, Hegel organiza suas obras maiores, ou seja, "Fenomenologia do Espírito", "Ciência da Lógica" e "Princípios da Filosofia do Direito" na "Enciclopédia das Ciências Filosóficas". A "Enciclopédia" permite, aos interessados no sistema filosófico hegeliano terem uma visão do todo, mesmo que seu caráter seja mais ligeiro, obviamente, do que os textos maiores. Hegel está claramente comprometido com os leitores e estudiosos de suas idéias. Tal postura é ainda mais confirmada na elaboração dos textos agrupados sob o título de "Propedêutica Filosófica", cujo público alvo são os alunos de Nürnberg. Nesses textos os alunos têm a possibilidade de entrar em contato com as idéias centrais da filosofia hegeliana que, apesar de manterem a tônica de Hegel sobre o real, isto é, marcadamente densas, procuram tornar-se significativas à compreensão ginasiana. O esforço empreendido por Hegel denota o reconhecimento da história e do contexto no qual sua filosofia se situa. Em outras palavras, segundo o próprio Hegel, a filosofia ao se manifestar somente após o acontecer da história recebe da mesma história as indicações sobre como se manifestar. O "como" se traduz nas formas de sensibilização do ouvinte ou do leitor. Não se trata de fazer concessões, mas de reconhecer o que tem ocorrido e como tem assumido suas formas específicas. O reconhecimento do que tem sido feito é o concomitante reconhecimento do que tem sido pensado. No entanto, é necessária a leitura atenta e cuidadosa das formas ou manifestações do pensar, pois não se trata de uma mera transposição do pensar para o real. Este último não é 
uma extensão do pensar, mas é uma realidade em si que, embora dependente da ação do pensar, não se configura como uma simples projeção.

A filosofia torna-se pertinente ao assumir a história humana com as questões que são determinantes para os homens. A filosofia, por estar inserida na história humana, deve aí se fazer presente, mas Hegel entende que não a qualquer preço porque a filosofia somente pode contribuir se respeitar o que lhe é específico e particular. O específico e particular da filosofia está em sua análise radical, rigorosa e de conjunto do real. O acesso à atitude filosófica não tem outro caminho senão através do contato com o pensar e fazer filosóficos nos textos dos próprios filósofos. Conhecer o que se fez até então na filosofia significa conhecer o que foi pensado, e procurar compreender tal pensar implica o desenvolvimento do pensar filosófico. Dessa forma Hegel atribui papel determinante ao conteúdo do ensino de filosofia, pois esta não se dissocia do que tem produzido. Portanto, não se aprende filosofia senão filosofando e isto advém necessariamente da apreensão da história da filosofia.

A aprendizagem da filosofia ou do filosofar através de sua história também indica que, para Hegel, ninguém aprende sozinho, mas sempre através da mediação de um outro. O professor, os colegas, os textos são mediações pelas quais a aprendizagem se realiza. A mediação é o momento pelo qual o real se efetiva ou obtém status do ser como existente. Entre os textos e os colegas destaca-se a mediação do professor, pois este pode atuar como uma mediação mediada, isto é, que já assumiu para si a história da filosofia. Mais do que um facilitador o professor se põe como um paradigma para os alunos, uma vez que ele mesmo não chega à história da filosofia senão através da experiência pessoal com ela. O professor também não é um reprodutor, pois sua mediação não determinará como a história da filosofia deverá ser compreendida, visto que o processo do filosofar produz o filósofo e este, como tal, poderá continuar indagando. Além disso, a mediação situa sempre a perspectiva do todo ou da superação da singularidade pela relação com algo mais.

O ensino da filosofia, para Hegel, pode e deve estender-se a todas as pessoas, mas isso não se faz sem exigências e de qualquer modo. Não há acesso à filosofia senão através de sua história, que não é outra coisa senão a manifestação do pensamento humano, conforme a própria compreensão hegeliana de filosofia, ou seja, apreensão da história no pensamento.

NOVELLI, P. G. A. The teaching of philosophy according to Hegel. Trans/Form/Ação, (São Paulo), v.28(2), 2005, p.129-148. 
- ABSTRACT: Is it possible to teach philosophy? The German philosopher G. W. F. Hegel (1770-1831) not only answers positively to such question but also indicates what has to be taught in philosophy and how. Hegel's answer has as its source his activity in the High School of Nürnberg where he searches to establish the aims and the procedures so that philosophy may be taught to the young people. According to Hegel philosophy is always meaningful when it considers what is basic for men, i.e., their life with all the questions related to it. In this way philosophy has to assume the man as its object. This ends up in the consideration of the human reality as it is so that it may be better and deeper understood through reflection and speculation. These abilities can only be obtained by the direct contact with philosophy itself in what is its specifications in its historical production or in other words, its texts. To know the history of philosophy is already to learn philosophy but such learning process needs the mediation of a teacher because one does not learn naturally nor spontaneously. To learn is to learn together with someone else.

- KEYWORDS: abstraction, dialectic, speculation

\section{Referências bibliográficas}

BRIEFE VON UND NA HEGEL. Friedhelm Nicolin. Org. Akademie Verlag, Berlin, 1978, 480p.

HEGEL, G.W.F. Ciencia de la Lógica. Trad. Augusta e Rodolfo Mondolfo. Buenos Aires: Solar S.A e Hachette, 1968, 754p.

Enciclopédia das Ciências Filosóficas em Epítome. Trad. de Artur Morão. Lisboa: Ed. 70, 1988, 240p.

Fenomenologia do Espírito. Trad. de Paulo Meneses e Karl-Heinz Efken. Petrópolis: Ed. Vozes, 1992, 269p.

Introdução à história da filosofia. Trad. de Artur Morão. Lisboa: Ed. 70, 1991, 253p.

Lecciones sobre la filosofía de la história universal. Trad. de José Gaos. Madrid: Alianza Editorial, 1989, 701p. (a)

Nürnberg und Heideçberg Schriften 1808-1817. Red. Eva Moldenhauer und Karl Marcus Michel. Frankfurt am Main: Suhrkamp, 1970, 623p.

Princípios da Filosofia do Direito. Trad. Orlando Vitorino. São Paulo: Martins Fontes, 2000, 329p.

Propedêutica Filosófica. Trad. de Artur Morão. Lisboa: Ed. 70, 1989, 385p..(b)

System der Sittlichkeit. Hersg. von Horst D. Brandt. Hamburg: Felix Meiner Verlag, 2002, 85p.

ROSENKRANZ, K. G.W.F. Hegels Leben. Berlin, 1844, 489p. 